\title{
CORRECTION
}

\section{Correction to: Different techniques for Alzheimer's disease classification using brain images: a study}

\author{
Published online: 16 November 2021 \\ (c) Springer-Verlag London Ltd., part of Springer Nature 2021

\section{Correction to: \\ International Journal of Multimedia Information \\ Retrieval \\ https://doi.org/10.1007/s13735-021-00210-9}

Ruhul Amin Hazarika ${ }^{1}$. Ajith Abraham ${ }^{2}$. Samarendra Nath Sur ${ }^{3} \cdot$ Arnab Kumar Maji $^{1} \cdot$ Debdatta Kandar $^{1}$

At the beginning of the second paragraph of Section 1.1 (page 2), these sentences were accidentally omitted in the editing process and were intended to provide context for reference [19] which is not referred to in the main text:

Some of the AD diagnosing approaches discussed in Table 1, have also been widely used to classify some other diseases. For example, Electronystagmography (EVestG) is an effective approach for diagnosing AD [18] as well as Parkinson's disease [19], but a possible limitation of the technique is that, it depends on the physical conditions/movements of the patients [19].

Publisher's Note Springer Nature remains neutral with regard to jurisdictional claims in published maps and institutional affiliations.

The original article can be found online at https://doi.org/10.1007/ s13735-021-00210-9.

\footnotetext{
Ruhul Amin Hazarika

rahazarika@gmail.com

$\bowtie$ Debdatta Kandar

kdebdatta@gmail.com

Ajith Abraham

abraham.ajith@gmail.com

Samarendra Nath Sur

samar.sur@gmail.com

Arnab Kumar Maji

arnab.maji@gmail.com
}

1 Department of Information Technology, North Eastern Hill University, Shillong, Meghalaya 793022, India

2 Machine Intelligence Research Labs (MIR Labs) Scientific Network for Innovation and Research Excellence Auburn, Washington 98071, USA

3 Department of Electronics and Communication Engineering, Sikkim Manipal Institute of Technology, Sikkim Manipal University, Majitar, Sikkim 737136, India 